\title{
The management of acute appendicitis in liver transplant patients: How effective is the Alvarado score?
}

\author{
Volkan Ince, ${ }^{1}$ Bora Barut, ${ }^{1}$ Fatih Ozdemir, ${ }^{1}$ Veysel Ersan, ${ }^{1}$ Koray Kutluturk, ${ }^{1}$ Fatih Gonultas, ${ }^{1}$ \\ Asim Onur, ${ }^{1}$ Burak Isik, ${ }^{1}$ Ramazan Kutlu, ${ }^{2}$ Sezai Yilmaz ${ }^{1}$ \\ ${ }^{1}$ Department of General Surgery, Inonu University, Liver Transplantation Institute, Malatya, Turkey \\ 2Department of Radiology, Inonu University, Liver Transplantation Institute, Malatya, Turkey
}

\begin{abstract}
OBJECTIVE: The incidence of acute appendicitis after liver transplantation (LT) is extremely low, reported to be $0.09 \%$ to $0.49 \%$, but the efficacy of the Alvarado score in this patient group has not been studied. This study was an investigation of the clinical management of patients who developed acute appendicitis after LT and the usefulness of the Alvarado score in the diagnosis.
\end{abstract}

METHODS: The study was performed using the data of 7 patients treated for acute appendicitis who were among 1990 patients who underwent LT between March 2002 and July 2017. The Alvarado score of the patients was calculated and reliability was analyzed.

RESULTS: In this study, the incidence of acute appendicitis in LT patients was $0.35 \%$. All of the patients were in the adult age group; $86 \%$ were male. The mean age was $46.4 \pm 10.7$ years and the timeframe for the development of appendicitis after transplantation was a median of 12 months (range: 4-101 months). The median Alvarado score was 7 (range: 5-9). All of the patients had an Alvarado score above 5 and $71 \%$ had a score of 7 or more.

CONCLUSION: Acute appendicitis is very rare in LT patients. As with non-transplant patients, Alvarado scoring can be safely performed in LT patients.

Keywords: Acute appendicitis; Alvarado; liver transplant.

T he incidence rate of acute appendicitis following liver transplantation (LT) has been reported as $0.09 \%$ to $0.49 \%$, and thus far, the largest case series cited in the English-language medical literature are 6 reports, which include a total of 32 cases worldwide $[1-10]$. The present study found an incidence of appendicitis developing after LT of $0.35 \%(7 / 1990)$, and is the third largest case series in the literature. In this special immunosuppressed patient group, acute appendicitis can become complicated due to a delay in diagnosis, resulting in a prolonged hospital stay. The diagnosis is based on

Received: July 07, 2017 Accepted: July 16, 2017 Online: October 24, 2017

Correspondence: Dr. Volkan Ince. Inonu University Medical School Department of Genelral Surgery 44280, Malatya, Turkey. Tel: +90 42234106 60-61 03 e-mail: volkanince@outlook.com

(c) Copyright 2017 by Istanbul Northern Anatolian Association of Public Hospitals - Available online at www.kuzeyklinikleri.com 
physical and radiological examinations (especially computed tomography). Thus far, there has been no evaluation in the medical literature of the use of the Alvarado scoring system in the diagnosis of acute appendicitis following LT. Though the traditional treatment is open appendectomy, in recent years, case presentations of laparoscopic appendectomy have been reported [1-3]. In this study, the diagnostic efficacy of the Alvarado score in 7 patients who developed acute appendicitis after LT and the clinical management of acute appendicitis in this special patient group were investigated.

\section{MATERIALS AND METHODS}

The prospective data of 1990 LT patients (1591 transplantations from living donors, and 399 from cadaveric donors) who were operated on between March 2002 and July 2017 and were registered in our data bank were retrospectively reviewed, and among them 7 patients who were treated for acute appendicitis were included in the analysis. The diagnostic methods used; the clinical, laboratory, and radiological characteristics; the Alvarado score; antibiotherapies applied; surgical findings; and the clinical course was examined and analyzed.

\section{RESULTS}

In this study, the incidence of acute appendicitis following LT was estimated at $0.35 \%$ (7/1990). The demographic data of the patients are presented in Table 1 . All of the patients were in the adult age group; $86 \%$ of them were male. The mean age of the patients was $46.4 \pm 10.7$ years. A median period of 12 months (range: 4-101 months) passed between LT and the development of appendicitis. The median Alvarado score was 7 points (range: $5-9$ points. The Alvarado score was greater than 5 in all patients, and in $71 \%$, the score was greater than 7 points. In all pa-

TABLE 1. Demographic data of the patients

\begin{tabular}{|c|c|c|c|c|c|c|c|}
\hline Parameter & Case 1 & Case 2 & Case 3 & Case 4 & Case 5 & Case 6 & Case 7 \\
\hline Age (years) & 54 & 38 & 40 & 36 & 49 & 42 & 66 \\
\hline Gender & Male & Male & Male & Female & Male & Male & Male \\
\hline Tx etiology & HBV & HBV & $\mathrm{HBV}+\mathrm{HDV}$ & HBV & $\mathrm{HBV}+\mathrm{HCC}$ & Cryptogenic & HBV (fulminant) \\
\hline Type of Tx & $\begin{array}{l}\text { Cadaver } \\
\text { (full-size) }\end{array}$ & $\begin{array}{c}\text { LDLT } \\
\text { (Right lobe) }\end{array}$ & $\begin{array}{c}\text { LDLT } \\
\text { (Right lobe) }\end{array}$ & $\begin{array}{l}\text { Cadaver } \\
\text { (full-size) }\end{array}$ & $\begin{array}{c}\text { LDLT } \\
\text { (Right lobe) }\end{array}$ & $\begin{array}{c}\text { LDLT } \\
\text { (Right lobe) }\end{array}$ & $\begin{array}{l}\text { Cadaver } \\
\text { (full-size) }\end{array}$ \\
\hline $\begin{array}{l}\text { Interval between Tx } \\
\text { and development } \\
\text { of appendicitis (months) }\end{array}$ & ) & 10 & 19 & 101 & 4 & 19 & 8 \\
\hline Etiology of appendicitis & Fecalith & Fecalith & Fecalith & Unknown & Fecalith & Fecalith & Fecalith \\
\hline CMV PCR & Negative & Negative & Unknown & Negative & Unknown & Unknown & Negative \\
\hline Perforation & Yes & No & No & No & Yes & No & Yes \\
\hline Surgical incision & Right paramedian & n Mc Burney & Mc Burney & Mc Burney & Mc Burney & Mc Burney & Mc Burney \\
\hline Alvarado score & 8 & 7 & 5 & 9 & 7 & 6 & 8 \\
\hline Hospital stay (days) & 7 & 5 & 5 & 2 & 10 & 4 & 10 \\
\hline $\begin{array}{l}\text { Post-appendectomy } \\
\text { follow-up } \\
\text { period (months) }\end{array}$ & 66 & 55 & 39 & 34 & 18 & 14 & 1 \\
\hline Time since Tx (months) & 78 & 65 & 58 & 135 & 22 & 33 & 9 \\
\hline
\end{tabular}

CMV: Cytomegalovirus; HBV: Hepatitis B virus; HCC: Hepatocellular carcinoma; HDV: Hepatitis delta virus; LDLT: Living donor liver transplantation; PCR: Polymerase chain reaction; Tx: Transplantation. 
tients, nausea or vomiting, tenderness, and rebound phenomenon localized in the right iliac region were present, and the most frequent symptom was loss of appetite, observed in $71 \%$. Migration of pain, fever and leukocytosis $\left(>10.000 / \mathrm{mm}^{2}\right)$ were seen in $43 \%$ of the patients. Elevated C-reactive protein (CRP) levels were detected (median: $7.1 \mathrm{mg} / \mathrm{dL}$; range: 1.4-19.1 mg/dL; normal: $0-0.035 \mathrm{mg} / \mathrm{dL}$ ) in all patients. All patients underwent ultrasonographic examination, and computed tomography (CT) was performed for $57 \%$. During the ultrasonographic examination, the median diameter of the appendix measured $8 \mathrm{~mm}$ (range: $6-11 \mathrm{~mm}$ ). In 3 patients, the appendix could not be visualized in the ultrasonogram; however, periappendicular abscess was detected. The diameter of the appendix of these 3 patients was 15, 10 and $6 \mathrm{~mm}$, and the diagnosis of appendicitis was confirmed (Fig. 1A, B).

All patients underwent open appendectomy. In 1 patient, a right paramedian incision was used; all other appendectomies were performed through a McBurney incision without any complication (Fig. $1 C, D) . A$ drain was inserted into surgical field in
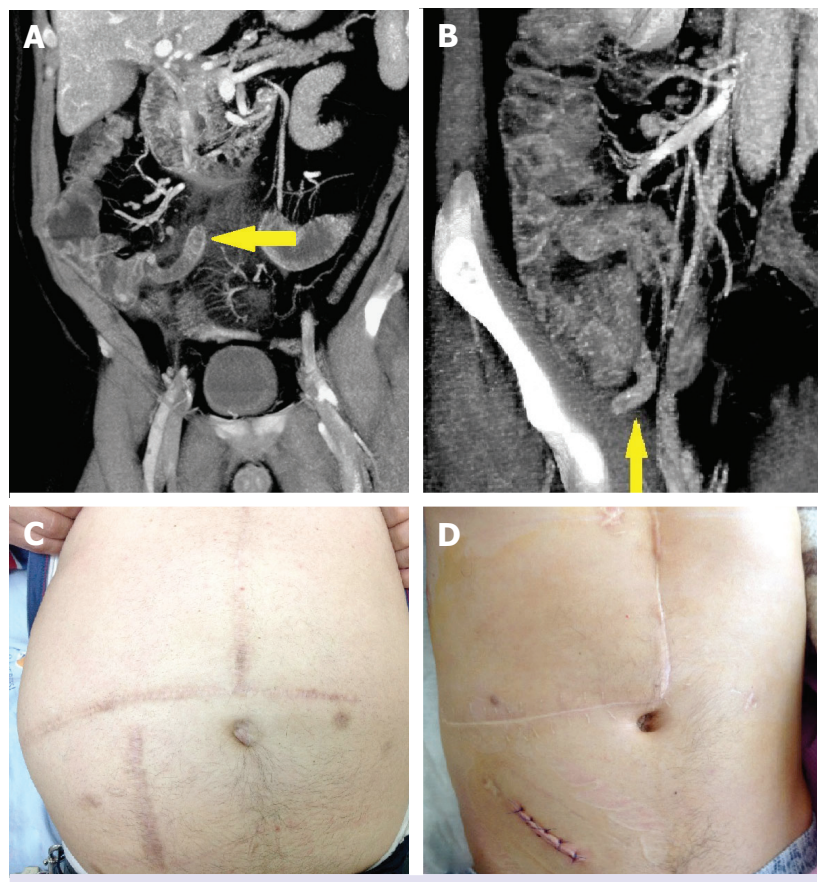

FIGURE 1. (A, B) Preoperative computed tomography scan indicating acute appendicitis. (C, D) Postoperative incision scars of the same patient
TABLE2. Alvarado score for acute appendicitis

Score (points)

$\begin{array}{lc}\text { Symptoms } & \\ \quad \text { Migratory pain } & 1 \\ \text { Loss of appetite } & 1 \\ \quad \text { Nausea and vomiting } & 1 \\ \text { Findings } & \\ \quad \text { Tenderness of the lower right quadrant } & 2 \\ \quad \text { Rebound phenomenon } & 1 \\ \quad \text { Fever }\left(>37.3^{\circ} \mathrm{C}\right) & 1 \\ \text { Laboratory results } & \\ \quad \text { Leukocytosis }\left(>10.000 / \mathrm{mm}^{3}\right) & 2 \\ \quad \text { Left shift (neutrophil count }>75 \%) & 1 \\ \text { Total score } & 10\end{array}$

Prediction of acute appendicitis; 0-4: Very low probability; 5-6: Probable (Confirm with computed tomography); 7-8: Higher probability; 9-10: Acute appendicitis.

a total of 4 cases with perforation (43\%) or strong adhesions to adjacent structures (14\%). Routine treatment with ceftriaxone and metronidazole was administered. In perforated cases, broad spectrum antibiotherapy (piperacillin-tazobactam alone or in combination with tigecycline) was initiated.

In $57 \%$ of the patients, cytomegalovirus (CMV) polymerase chain reaction test was performed in peripheral blood samples, and no evidence of CMV was detected. Histopathology reports indicated the presence of a perforated appendicitis (43\%), suppurative appendicitis and local peritonitis $(28.5 \%)$, and acute appendicitis (28.5\%).

The median length of hospital stay was 7 days (range: 7-10 days) for patients with a perforation, and 4.5 days (range: $2-5$ days) for those without, and the intergroup difference was statistically significant $(p=0.02)$.

The median follow-up period after the appendectomy was 34 months (range: 1-66 months), and 58 months (range: 9-135 months) after the LT. No post-appendectomy mortality or morbidity was encountered. At the time of writing, all of the patients are living with functional grafts. 


\section{DISCUSSION}

Acute appendicitis may lead an atypical course in the immunosuppressed patient group. Therefore, though the development of acute appendicitis following LT is extremely rare, delay in diagnosis increases the probability of complication. Alvarado scoring may reportedly decrease the rate of negative appendectomies (Table 2) [11]. In this study, contrary to expectations, the disease did not lead an atypical course. Right lower quadrant pain and tenderness, nausea and vomiting, the presence of rebound phenomenon, increased CRP level, ultrasonographically detected dilated appendix or periappendicular abscess, and an Alvarado score $\geq 5$ in all patients facilitated establishment of the diagnosis. Observation of some typical symptoms, such as loss of appetite, and an Alvarado score of $\geq 7$ in most of the patients further substantiated the diagnosis. Another important finding of our study is that other significant symptoms of acute appendicitis, including leukocytosis, fever, and migratory pain, were detected in less than half (43\%) of our patients; however, the absence of these symptoms in this special patient group did not make acute appendicitis less likely.

In the diagnosis of acute appendicitis, use of CT has generally been recommended for patients with an Alvarado score of 5-6 points, and for patients with a scores $\geq 7$ points, surgical treatment is recommended [12]. However, to the best of our knowledge, no study has yet been performed concerning the use of the Alvarado score in the management of acute appendicitis in LT patients. The Alvarado scoring system is not widely used at our center in the diagnosis of acute appendicitis. The relevant history, physical examination, laboratory results consistent with acute appendicitis, and a dilated (diameter $\geq 6$ $\mathrm{mm}$ ) and inflamed (wall thickness $\geq 3 \mathrm{~mm}$ ) appendix observed on ultrasound are sufficient for the diagnosis. If the appendix cannot be visualized on ultrasound, then the diagnosis is confirmed with CT. In our study, $\mathrm{CT}$ established the diagnosis of acute appendicitis in 3 such cases. CT demonstrated the presence of a periappendicular abscess and collection. The ultrasonographic examination 1 patient who also underwent CT demonstrated the presence of dilated appendicitis, so the CT of this patient was unnecessary and merely confirmed the diagnosis. If we had used the Alvarado score, since this patient had a score of 5 points, a CT still would have been performed and the conclusion would have been the same. Use of the Alvarado score does not necessarily decrease the number of CTs obtained. If treatment is planned based on this scoring system, then a $C T$ is obtained for patients with an Alvarado score of 5-6 points, and those with a score of 7 points or more would be operated on without resorting to CT. As it was, all of our patients were diagnosed as acute appendicitis and treatment was successfully achieved.

Cases complicated by a perforation had a significantly prolonged hospital stay compared with those without a perforation (median hospital stay 7 days and 4.5 days, respectively). The use of the Alvarado score and CT may aid in the establishment of early diagnosis and treatment.

Treatment of acute appendicitis is achieved with an open surgical or laparoscopic appendectomy. We preferred to perform an open appendectomy, though in recent years, cases managed with a laparoscopic appendectomy have been reported with promising outcomes [1-3].

\section{CONCLUSION}

Acute appendicitis is very rarely seen in LT patients; however, its clinical manifestations resemble typical appendicitis. However, leukocytosis, fever, and migratory pain were seen in fewer than half of the patients in this study. The Alvarado scoring system can be used safely in this patient group; however, it does not decrease the number of unnecessary CT scans. In cases with a perforation, the hospital stay is prolonged. Either an open or a laparoscopic appendectomy may be used to treat acute appendicitis.

Conflict of Interest: No conflict of interest was declared by the authors.

Financial Disclosure: The authors declared that this study has received no financial support.

Authorship contributions: Concept - V.I.; Design - B.B.; Supervision - B.I.; Materials - V.E., A.O., K.K.; Data collection \&/or processing - R.K.; Analysis and/or interpretation - V.I.; Literature search - B.B.; Writing - V.I.; Critical review - S.Y. 


\section{REFERENCES}

1. Huang JF, Ma JF, Gong Y, Yu LL, Cui CX, Yang LX, et al. Acute Appendicitis in the Early Stage after Orthotopic Liver Transplantation. Chin Med J (Engl) 2017;130:1253-4. [CrossRef]

2. Fonseca-Neto OC, Lima HC, Melo PS, Lemos R, Leitão L, Amorim AG, et al. Acute apendicitis in liver transplant recipients. Arq Bras Cir Dig 2016;29:30-2. [CrossRef]

3. McCarty TP, Lee RA, Herfel BM, Pappas PG. Cytomegalovirus appendicitis in solid organ transplant patients, two cases and a review. J Clin Virol 2015;66:48-50. [CrossRef]

4. Wei CK, Chang CM, Lee CH, Chen JH, Yin WY. Acute appendicitis in organ transplantation patients: a report of two cases and a literature review. Ann Transplant 2014;23;19:248-52.

5. Quartey B, Dunne J, Cryer C. Acute appendicitis post liver transplant: a case report and literature review. Exp Clin Transplant 2012;10:183-5. [CrossRef]

6. Aktas S, Sevmis S, Karakayali H, Ozcay F, Coskun M, Bilezikci
$B$, et al. Acute appendicitis after diaphragmatic hernia after pediatric liver transplant. Exp Clin Transplant 2011;9:63-7.

7. Wu L, Zhang J, Guo Z, Tai Q, He X, Ju W, et al. Diagnosis and treatment of acute appendicitis after orthotopic liver transplant in adults. Exp Clin Transplant 2011; 9:113-7.

8. Ceulemans P, Wybaillie E, Monbaliu D, Aerts R, Pirenne J. Acute appendicitis after liver transplantation: a case report and review of the literature. Acta Chir Belg 2010;110:335-8.

9. Savar A, Hiatt JR, Busuttil RW. Acute appendicitis after solid organ transplantation. Clin Transplant 2006;20:78-80. [CrossRef]

10. Abt PL, Abdullah I, Korenda K, Frank A, Peterman H, Stephenson GR, et al. Appendicitis among liver transplant recipients. Liver Transpl 2005;11:1282-4. [CrossRef]

11. Alvarado A. A practical score for the early diagnosis of acute appendicitis. Ann Emerg Med 1986;15:557-64. [CrossRef]

12. McKay R, Shepherd J. The use of the clinical scoring system by Alvarado in the decision to perform computed tomography for acute appendicitis in the ED. Am J Emerg Med 2007;25:489-93. 